Jurnal Sulolipu : Media Komunikasi Sivitas Akademika dan Masyarakat Vol. 21 No. 12021

e-issn : 2622-6960, p-issn : 0854-624X

\title{
PENGARUH INTENSITAS KEBISINGAN TERHADAP KEJADIAN SINDROMA VERTIGO PADA KARYAWAN UNIT PRODUKSI PT MARUKI INTERNATIONAL INDONESIA MAKASSAR
}

The Effect of Noise Intensity on the Event of Vertigo Syndrome in PT Maruki International Indonesia Makassar

Andi Nurhartati ${ }^{1}$, Musfirah ${ }^{2}$, Suryanti ${ }^{3}$

Sekolah Tinggi IImu Kesehatan Tamalatea Makassar

a.nurhartati@stiktamalateamks.ac.id, musfirah@stiktamalateamks.ac.id

\section{ABSTRACT}

The factory work environment in the Production Unit has a noise intensity that exceeds the Threshold Value (NAV), which not only causes discomfort but also can have serious effects on human health. The purpose of this study was to determine the relationship between noise intensity and the incidence of vertigo syndrome among employees of the production unit of PT Maruki International Indonesia Makassar. This research is an observational study with a Cross Sectional Study approach. The population in this study were all employees who were in the production unit 1 of PT Maruki International Indonesia Makassar. The sampling technique used the total sampling method as many as 49 employees. The variables studied were Noise Intensity, Working Period, Use of Ear Protection Equipment (APT) and vertigo syndrome. The instrument used was noise measurement using a Sound Level Meter (SLM) tool, employee characteristics data and vertigo syndrome were obtained from questionnaires and direct interviews. The results of this study indicate that there is an influence between the intensity of noise and the incidence of vertigo syndrome with a value of $\rho=0.031$, the use of APT with the incidence of vertigo syndrome with a value of $\rho=0.007$ and there is no influence between work tenure and the incidence of vertigo syndrome with a value of $\rho=0.755$. For this reason, companies need to enforce the rules for the use of the Occupational Safety and Health (K3) program maximally and consistently through comprehensive counseling at each work unit in the form of preventive measures to minimize the occurrence of occupational diseases, especially Vertigo Syndrome.

Keywords: Noise Intensity, Working Period, Use of APT, Vertigo Syndrome.

\section{ABSTRAK}

Lingkungan kerja pabrik di Unit Produksi memiliki intensitas kebisingan yang melebihi Nilai Ambang Batas (NAB), yakni tidak sekedar menimbulkan rasa tidak nyaman namun juga dapat menimbulkan efek serius bagi kesehatan manusia. Tujuan dari penelitian ini adalah untuk mengetahui hubungan antara intensitas kebisingan dengan kejadian sindroma vertigo pada karyawan unit produksi PT Maruki International Indonesia Makassar. Penelitian ini merupakan penelitian observasional dengan pendekatan Cross Sectional Study. Populasi dalam penelitian ini adalah seluruh karyawan yang berada di unit produksi 1 PT Maruki International Indonesia Makassar. Teknik pengambilan sampel dengan metode total sampling yaitu sebanyak 49 karyawan. Variabel yang diteliti adalah Intensitas Kebisingan, Masa Kerja, Penggunaan Alat Pelindung Telinga (APT) dan sindroma vertigo. Instrumen yang digunakan adalah pengukuran kebisingan dengan menggunakan alat Sound Level Meter (SLM), data karakteristik karyawan dan sindroma vertigo diperoleh dari kuesioner dan wawancara langsung. Hasil penelitian ini mengindikasikan bahwa ada pengaruh antara intensitas kebisingan dengan kejadian sindroma vertigo dengan nilai $\rho=0,031$, Penggunaan APT dengan kejadian sindroma vertigo dengan nilai $\rho=0,007$ dan tidak ada pengaruh antara masa kerja dengan kejadian sindroma vertigo dengan nilai $\rho=$ 0,755 . Untuk itu perusahaan perlu menegakkan aturan penggunaan program Keselamatan dan Kesehatan Kerja (K3) secara maksimal dan konsisten melalui penyuluhan secara menyeluruh pada setiap unit kerja berupa tindakan pencegahan dalam meminimalisasi terjadinya penyakit akibat kerja, khususnya Sindroma Vertigo. Kata kunci : Intensitas Kebisingan, Masa Kerja, Penggunaan APT, Sindroma vertigo.

\section{PENDAHULUAN}

Vertigo merupakan salah satu gangguan yang sering dialami dan menyusahkan sebagian besar manusia. Umumnya keluhan vertigo menyerang sebentar saja, hari ini terjadi, besok hilang. Namun, ada juga vertigo yang kambuh lagi setelah beberapa bulan atau beberapa tahun (Junaidi, 2013).

Seiring dengan perkembangan industri dewasa ini, maka tentunya akan menimbulkan berbagai faktor bahaya yang semakin beragam dan lebih luas. Hal ini tidak terlepas dari manajemen suatu perusahaan yang unggul dan cermat dalam melakukan suatu bentuk pengendalian yang efektif. Salah satunya adalah perlunya meningkatkan suatu bentuk pengendalian terhadap kebisingan dalam lingkungan kerja. Kenyataan ini banyak dijumpai bahwa tidaklah sedikit tenaga kerja yang merasakan dampak akibat kebisingan yang ditimbulkan oleh mesin-mesin produksi tersebut (Dedi, 2013).

PT Maruki sendiri berdasarkan data awal yang di peroleh dari Klinik Kesehatan, Jumlah keluhan terkait dengan pusing/vertigo sebanyak 73 Kasus pada bulan desember tahun 2017. Sedangkan pada tahun 2018 bulan april dengan angka 
Jurnal Sulolipu : Media Komunikasi Sivitas Akademika dan Masyarakat Vol. 21 No. 12021

e-issn : 2622-6960, p-issn : 0854-624X

tertinggi sebanyak 92 kasus (Bagian K3 dan Klinik, PT. Maruki, 2018).

Penelitian ini bertujuan untuk mengetahui pengaruh intensitas kebisingan terhadap kejadian sindroma vertigo, pengaruh masa kerja dengan terhadap kejadian sindroma kebisingan dan pengaruh alat pelindung telinga terhadap kejadian sindroma kebisingan pada karyawan Unit Produksi 1 PT. Maruki International Indonesia Makassar.

\section{METODE PENELITIAN}

Jenis penelitian yang digunakan adalah observasional dengan pendekatan Cross Sectional Study yaitu variabel independen dan variabel dependen diambil pada periode waktu yang sama untuk mengetahui pengaruh antara intensitas kebisingan, masa kerja, dan penggunaan Alat Pelindung Telinga (APT) terhadap kejadian sindroma vertigo, yang diukur melalui wawancara (voice jarak jauh) dan menggunakan kuesioner dengan dalam bentuk (google form) yang merupakan penjabaran dari setiap variabel yang diteliti pada karyawan Unit Produksi PT Maruki International Indonesia Makassar. Hipotesis yang diuji adalah hipotesis nol $(\mathrm{Ho})$ dengan derajat kemaknaan $(\alpha)=0,05$, uji statistik yang digunakan adalah $\mathrm{Chi}$ Square.

\section{HASIL DAN PEMBAHASAN}

1. Karakteristik Variabel yang Diteliti

\section{a. Intensitas kebisingan}

Tabel 1. Distribusi responden berdasarkan Intensitas Kebisingan pada Unit Produksi 1 PT Maruki Makassar

\begin{tabular}{ccc}
\hline $\begin{array}{c}\text { Intensitas } \\
\text { Kebisingan }\end{array}$ & $\begin{array}{c}\text { Frekuensi } \\
(\mathrm{n})\end{array}$ & $\begin{array}{c}\text { Persentase } \\
(\%)\end{array}$ \\
\hline $\begin{array}{c}\text { bising tinggi } \\
\geq 85 \mathrm{~dB}\end{array}$ & 44 & 89.8 \\
\hline $\begin{array}{c}\text { bising rendah } \\
<85 \mathrm{~dB}\end{array}$ & 5 & 10.2 \\
\hline Total & 49 & 100.0
\end{tabular}

Sumber: Data Primer, 2020.

Tabel 1, Menunjukkan bahwa sebagian besar responden yang bekerja dengan Intensitas Kebisingan yang tinggi yakni 44 orang $(89,8 \%)$ dan responden yang bekerja dengan Intensitas Kebisingan rendah yakni 5 orang $(10,2 \%)$.

b. Masa kerja

Tabel 2. Distribusi responden berdasarkan

Masa Kerja pada Unit Produksi 1 PT Maruki Makassar

\begin{tabular}{ccc} 
Masa Kerja & $\begin{array}{c}\text { Frekuensi } \\
(\mathrm{n})\end{array}$ & $\begin{array}{c}\text { Persentase } \\
(\%)\end{array}$ \\
\hline $\begin{array}{c}\text { Lama } \geq 5 \\
\text { Tahun }\end{array}$ & 37 & 75,5 \\
\hline $\begin{array}{c}\text { Baru }<5 \\
\text { Tahun }\end{array}$ & 12 & 24,5 \\
\hline Jumlah & 49 & 100,0
\end{tabular}

Sumber: Data Primer, 2020.

Tabel 2. Menunjukkan bahwa sebagian besar responden memiliki masa kerja yang lama yakni 37 orang $(75,5 \%)$ dan responden yang memiliki masa kerja yang baru yakni 12 orang $(24,5 \%)$.

\begin{tabular}{|c|c|c|}
\hline \multicolumn{3}{|c|}{$\begin{array}{l}\text { c. Penggunaan Alat Pelindung Telinga } \\
\text { (APT) } \\
\text { Tabel 3. Distribusi Responden } \\
\text { Berdasarkan Penggunaan Alat } \\
\text { Pelindung Telinga (APT) pada Unit } \\
\text { Produksi } 1 \text { PT Maruki International } \\
\text { Indonesia Makassar }\end{array}$} \\
\hline \multicolumn{3}{|c|}{ Alat Frekuensi Persentase } \\
\hline \multirow{2}{*}{$\begin{array}{c}\text { Tidak } \\
\text { Menggunakan } \\
\text { Menggunakan }\end{array}$} & 20 & 40,8 \\
\hline & 29 & 59,2 \\
\hline Jumlah & 49 & 100,0 \\
\hline
\end{tabular}

Sumber: Data Primer, 2020.

Tabel 3. Menunjukkan bahwa responden yang Tidak menggunakan APT saat bekerja sebanyak 20 orang $(40,8 \%)$, sedangkan responden yang menggunakan APT saat bekerja sebanyak 29 orang $(59,2 \%)$ responden. 
Jurnal Sulolipu : Media Komunikasi Sivitas Akademika dan Masyarakat Vol. 21 No.12021

e-issn : 2622-6960, p-issn : 0854-624X

\section{d. Sindroma Vertigo}

Tabel 4. Distribusi Responden

Berdasarkan Kejadian Sindroma Vertigo pada Unit Produksi 1 PT Maruki Maruki International Indonesia Makassar

\begin{tabular}{ccc}
$\begin{array}{c}\text { Sindroma } \\
\text { Vertigo }\end{array}$ & $\begin{array}{c}\text { Frekuensi } \\
(\mathrm{n})\end{array}$ & $\begin{array}{c}\text { Persentase } \\
(\%)\end{array}$ \\
\hline $\begin{array}{c}\text { Tidak } \\
\text { Menderita }\end{array}$ & 21 & 42,9 \\
\hline Menderita & 28 & 57,1 \\
\hline Jumlah & 49 & 100,0
\end{tabular}

Sumber: Data Primer, 2020

Tabel 4. Menunjukan bahwa responden yang tidak menderita sindroma vertigo sebanyak 21 orang $(42,9 \%)$. dan responden yang mederita sindroma vertigo sebanyak 28 orang $(57,1 \%)$.

\section{Analisis Pengaruh Antara Variabel Independen dengan Variabel Dependen}

a. Pengaruh Intensitas Kebisingan dengan kejadian Sindroma Vertigo

Tabel 5. Pengaruh Masa Kerja Dengan kejadian Sindroma Vertigo pada Unit Produksi 1 PT Maruki International Indonesia Makassar

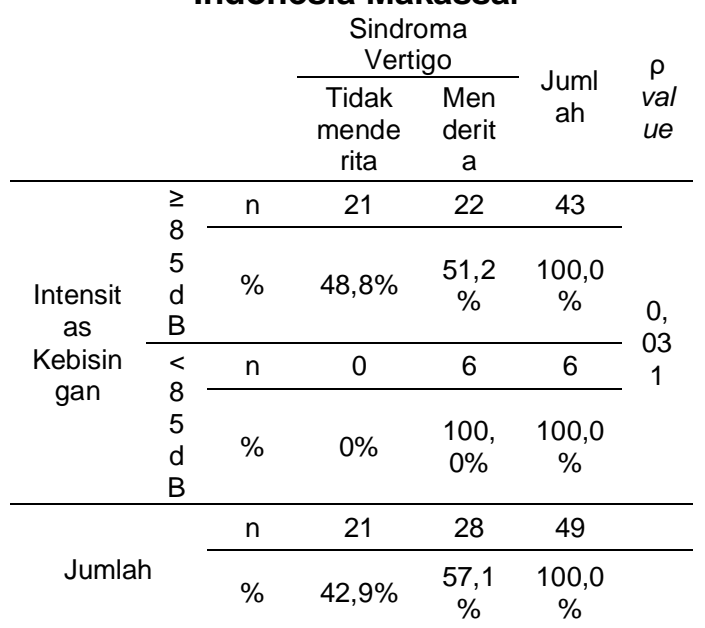

Sumber : Data Primer. 2020.

Secara statistik dengan menggunakan analisis uji Chi Square diperoleh $\rho=0,031$ $<$ nilai $\rho$ standar $(0,05)$ sehingga Ho ditolak dan Ha diterima dengan interpretasi bahwa Intensitas Kebisingan berpengaruh secara signifikan dengan kejadian Sindroma Vertigo.

\section{b. Pengaruh Masa Kerja dengan kejadian Sindroma Vertigo}

Tabel 6. Pengaruh Masa Kerja Dengan kejadian Sindroma Vertigo pada Unit Produksi 1 PT Maruki International Indonesia Makassar

\begin{tabular}{|c|c|c|c|c|c|c|}
\hline & & & \multicolumn{2}{|c|}{ Sindroma Vertigo } & \multirow[b]{2}{*}{$\underset{\mathrm{h}}{\underset{\mathrm{Jumla}}{\mathrm{n}}}$} & \multirow{2}{*}{$\begin{array}{c}\rho \\
\text { valu } \\
e\end{array}$} \\
\hline & & & $\begin{array}{c}\text { Tidak } \\
\text { menderi } \\
\text { ta }\end{array}$ & $\begin{array}{c}\text { Menderi } \\
\text { ta }\end{array}$ & & \\
\hline \multirow{4}{*}{$\begin{array}{c}\text { Mas } \\
\text { a } \\
\text { kerj } \\
\text { a }\end{array}$} & Lam & $\mathrm{n}$ & 16 & 20 & 36 & \multirow{4}{*}{$\begin{array}{c}0,75 \\
5\end{array}$} \\
\hline & $\begin{array}{c}5 \\
\text { tahu } \\
n\end{array}$ & $\%$ & $44,4 \%$ & $55,6 \%$ & $\begin{array}{c}100,0 \\
\%\end{array}$ & \\
\hline & \multirow{2}{*}{$\begin{array}{c}\text { Bar } \\
\mathrm{u}< \\
5 \\
\text { tahu } \\
\mathrm{n}\end{array}$} & $\mathrm{n}$ & 5 & 8 & 13 & \\
\hline & & $\%$ & $38,5 \%$ & $61,5 \%$ & $\begin{array}{c}100,0 \\
\%\end{array}$ & \\
\hline \multirow{2}{*}{\multicolumn{2}{|c|}{ Jumlah }} & $\mathrm{n}$ & 21 & 28 & 49 & \\
\hline & & $\%$ & $42,9 \%$ & $57,1 \%$ & $\begin{array}{c}100,0 \\
\%\end{array}$ & \\
\hline
\end{tabular}

Sumber : Data Primer. 2020.

Tabel 6. Secara statistik dengan menggunakan analisis uji Chi Square diperoleh $\rho=0,709>$ nilai $\rho$ standar $(0,05)$ sehingga $\mathrm{Ho}$ diterima dan $\mathrm{Ha}$ ditolak dengan interpretasi bahwa masa kerja tidak berpengaruh secara signifikan dengan kejadian Sindroma Vertigo.

\section{c. Pengaruh Penggunaan APT Dengan kejadian Sindroma Vertigo}

Tabel 7. Pengaruh Penggunaan Alat

Pelindung Telinga Dengan kejadian Sindroma Vertigo pada Unit Produksi 1 PT Maruki International Indonesia Makassar

\begin{tabular}{|c|c|c|c|c|c|c|}
\hline & & & \multicolumn{2}{|c|}{$\begin{array}{l}\text { Sindroma } \\
\text { Vertigo }\end{array}$} & \multirow{2}{*}{$\begin{array}{l}\text { Juml } \\
\text { ah }\end{array}$} & \multirow{2}{*}{$\begin{array}{c}\rho \\
\text { val } \\
\text { ue }\end{array}$} \\
\hline & & & $\begin{array}{l}\text { tidak } \\
\text { mend } \\
\text { erita } \\
\end{array}$ & $\begin{array}{l}\text { Mend } \\
\text { erita }\end{array}$ & & \\
\hline \multirow{4}{*}{$\begin{array}{l}\mathrm{A} \\
\mathrm{P} \\
\mathrm{T}\end{array}$} & \multirow{2}{*}{$\begin{array}{l}\text { Menggu } \\
\text { nakan }\end{array}$} & $n$ & 18 & 13 & 31 & \multirow{6}{*}{$\begin{array}{l}0,0 \\
07\end{array}$} \\
\hline & & $\%$ & $\begin{array}{c}58,1 \\
\% \\
\end{array}$ & $\begin{array}{c}41,9 \\
\% \\
\end{array}$ & $\begin{array}{c}100 \\
0 \% \\
\end{array}$ & \\
\hline & \multirow{2}{*}{$\begin{array}{l}\text { Tidak } \\
\text { menggu } \\
\text { nakan }\end{array}$} & $n$ & 3 & 15 & 18 & \\
\hline & & $\%$ & $\begin{array}{c}16,7 \\
\%\end{array}$ & $\begin{array}{c}83,3 \\
\%\end{array}$ & $\begin{array}{c}100 \\
0 \%\end{array}$ & \\
\hline & \multirow[b]{2}{*}{ Jumlah } & $\mathrm{n}$ & 21 & 28 & 49 & \\
\hline & & $\%$ & $\begin{array}{c}42,9 \\
\%\end{array}$ & $\begin{array}{c}57,1 \\
\%\end{array}$ & $\begin{array}{l}100 \\
0 \%\end{array}$ & \\
\hline
\end{tabular}

Sumber : Data Primer. 2020 
Jurnal Sulolipu : Media Komunikasi Sivitas Akademika dan Masyarakat

Vol. 21 No. 12021

e-issn : 2622-6960, p-issn : 0854-624X

Tabel 7. Secara statistik dengan menggunakan analisis uji Chi Square diperoleh $\rho=0,007<$ nilai $\rho$ standar $(0,05)$ sehingga Ho ditolak dan $\mathrm{Ha}$ diterima dengan interpretasi bahwa penggunaan APT berpengaruh secara signifikan dengan kejadian Sindroma Vertigo.

\section{PEMBAHASAN}

\section{a. Pengaruh Intensitas Kebisingan dengan kejadian Sindroma Vertigo}

Hasil analisis hubungan antara intensitas kebisingan dengan kejadian sindroma vertigo menunjukan bahwa yang menderita sindroma vertigo pada responden dengan intensitas tinggi $\geq$ $85 \mathrm{~dB}$ sebesar $51,2 \%$ dan responden dengan intensitas rendah $<85 \mathrm{~dB}$ sebesar $100.0 \%$.

Hal ini berarti bahwa persentase kejadian sindroma vertigo lebih banyak ditemukan pada responden dengan intensitas kebisingan $\geq 85 \mathrm{~dB}$. Artinya responden dengan intensitas kebisingan $\geq 85 \mathrm{~dB}$ berpeluang lebih mengalami kejadian sindroma vertigo dibandikan dengan intensitas kebisingan $<85 \mathrm{~dB}$.

Menurut pedoman mengenai bising lingkungan kerja yang telah digariskan oleh Occupational Safety \& Health Act (OSHA), maka bising dalam keadaan tetap setinggi $\geq 85 \mathrm{~dB}$ dinyatakan sebagai bising berbahaya, bising penuh risiko yang umumnya banyak ditemukan pada industri.

Penelitian Evan dan Hyge, Munich 1998, bahwa kebisingan dapat menimbulkan stres yang ditandai dengan kenaikan hormon stres yang dibuktikan bahwa komunitas yang terpajan kebisingan tinggi mempunyai kadar hormon stres lebih tinggi dibanding komunitas di kebisingan rendah (Ridley, 2016).

Kebisingan merupakan salah satu faktor yang cukup penting dalam hubungannya dengan kesehatan dan keselamatan kerja. Dampak kebisingan yang merugikan kesehatan manusia, Menurut Luther Terry peneliti di Badan Bedah AS, yang melakukan penelitian adanya akibat negatif terkait suara yang bising, proses pendengaran melibatkan: kontruksi jantung, peredaran darah, meningkatkan kerja hati, pernafasan yang meningkat, menghambat penyerapan kulit dan tekanan kerangka otot, sistem pencernaan berubah, aktivitas yang berhubungan dengan kelenjar yang memberi pertanda pada zat-zat kimia dalam tubuh termasuk darah dan air seni, efek keseimbangan organ. Juga keseimbangan efek perasa dan perubahan kimia di otak. Itu semua merupakan sebagian dari efek suara bising pada manusia.

Gangguan faal yang dapat ditemukan pada pemaparan bising adalah gangguan keseimbangan/equilibrium disordes, dengan gejala-gejala seperti mual, vertigo dan nystagmus, aktivitas lambung menurun, tonus otot meningkat, perubahan biokimiawi/biological changes (kadar glukosa, urea, dan kolesterol dalam darah, darah katekolamin dalam air seni).

Hal ini sejalan dengan hasil penelitian ini yaitu ada hubungan antara intensitas kebisingan dengan kejadian sindroma vertigo, berdasarkan hasil wawancara yang dilakukan kepada karyawan, berpendapat bahwa mereka bekerja pada ruang yang penuh bising dengan intensitas $\geq 85 \mathrm{~dB}$ dan membutuhkan konsentrasi penuh pada saat bekerja agar dapat terhindar dari kecelakaan kerja, hal ini mengakibatkan karyawan mengalami berbagai keluhan kesehatan termasuk sindroma-vertigo.

b. Pengaruh Masa Kerja dengan kejadian Sindroma Vertigo

Hasil analisis hubungan antara masa kerja dengan kejadian sindroma vertigo menunjukan bahwa kejadian sindroma vertigo pada responden dengan masa kerja lama $\geq 5$ tahun sebesar $55,6 \%$ dan responden dengan masa kerja < 5 tahun sebesar $61,5 \%$. Hal ini berarti bahwa persentase kejadian sindroma vertigo lebih banyak ditemukan pada responden yang memiliki masa kerja $\geq 5$ tahun. Artinya responden yang memiliki masa kerja < 5 tahun berpeluang lebih mengalami kejadian sindroma vertigo dibandikan yang memiliki masa kerja $\geq 5$ tahun.. 
Jurnal Sulolipu : Media Komunikasi Sivitas Akademika dan Masyarakat Vol. 21 No. 12021

e-issn : 2622-6960, p-issn : 0854-624X

Menurut Manuaba, 1975 karyawan akan mengalami berbagai keluhan termasuk keluhan kesehatan apabila secara teknis lingkungan kerjanya tidak memenuhi syarat. Lingkungan kerja tersebut meliputi keseimbangan beban kerja dengan umur tenaga kerja. Semakin lama melakukan pekerjaan berarti umur semakin bertambah dan keluhan semakin meningkat pula (Mursalim, 2017).

Masa kerja adalah waktu karyawan bekerja atau lamanya pada unit produksi sampai pada saat dilakukanya penelitian. Semakin lama seseorang bekerja maka kemungkinan ia menderita penyakit yang diakibatkan oleh pekerjaannya semakin besar pula, baik secara langsung maupun tidak langsung dan tanpa ia sadari. Namun tidak dapat dipungkiri bahwa masa kerja akan mempengaruhi aktivitas kerja sebab semakin lama seseorang bekerja ditempat kerjanya, maka ia akan mengetahui banyak tentang situasi serta kondisi tempat bekerjanya tersebut dan semakin lama pula ia akan terpapar dengan hazard yang ada di tempat kerja.

Semakin lama masa kerja berarti semakin besar pula potensi mengalami gangguan kesehatan. Hal ini diakibatkan karena kondisi fisik semakin menurun seiring dengan bertambahnya umur seseorang. Semakin lama seseorang menekuni pekerjaannya atau profesinya itu berarti kondisi fisiknya semakin menurun (Riski, 2013). Hal ini berbanding terbalik dengan teori dan hasil penelitian yang dilakukan karena hasil dalam penelitian ini diperoleh bahwa tidak adanya hubungan antara masa kerja dengan kejadian sindroma vertigo karena tingkat risiko lebih cenderung kepada karyawan yang masa kerjanya baru atau < 5 tahun. Berdasarkan hasil wawancara yang dilakukan dengan karyawan, berpendapat bahwa keluhan hanya terjadi ketika karyawan mulai bekerja dilingkungan tersebut, hal ini disebabkan karena karyawan baru beradaptasi dengan lingkungan serta situasi yang penuh bising, sehinga karyawan dengan masa kerja baru $<5$ tahun lebih berisiko dibandingkan dengan karyawan dengan masa kerja lama atau $\geq 5$ tahun.

\section{c. Pengaruh Penggunaan APT Dengan kejadian Sindroma Vertigo}

Dalam penelitian ini peneliti tidak membedakan antara penggunaan APT ear muff dengan ear plug, hanya melihat pada besarnya pengaruh penggunaan APT terhadap kejadian sindroma vertigo.

Hasil analisis hubungan antara penggunaan Alat Pelindung Telinga (APT) dengan kejadian sindroma vertigo menunjukan bahwa yang menderita sindroma vertigo pada responden yang menggunakan APT sebesar $41,9 \%$ dan responden yang tidak menggunakan APT sebesar $83,3 \%$. Hal ini berarti bahwa persentase kejadian sindroma vertigo lebih banyak ditemukan pada responden yang tidak menggunakan APT. Artinya responden yang tidak menggunakan APT berpeluang lebih besar mengalami kejadian sindroma vertigo dibandingkan yang menggunakan APT.

Berdasarkan hasil penelitian ini menunjukkan bahwa dari 49 karyawan yang menyatakan telah disediakannya APT oleh perusahaan namun masih terdapat 15 karyawan yang pernah menderita sindroma vertigo, dalam penelitian ini karyawan yang berisiko terkena sindrom vertigo adalah karyawan yang saat bekerja tidak menggunakan alat pelindung telinga dikarena pajanan kebisingan yang berlebihan memicu terjadinya penyakit akibat kerja, dan meskipun karyawan yang menggunakan APT tetapi tetap mengalami sindroma vertigo. Hal ini dapat disebabkan oleh penggunaan APT oleh karyawan belum secara baik dan benar ataupun bisa jadi kelayakan alat yang digunakan sudah tidak memenuhi syarat penggunaan.

Berdasarkan hasil wawancara yang dilakukan serta pendalaman pertanyaan, ditemukan bahwa sebagian dari karyawan mengatakan keluhan pusing, sedangkan terasa berkurang apabila karyawan tidak 
Jurnal Sulolipu : Media Komunikasi Sivitas Akademika dan Masyarakat

Vol. 21 No.12021

e-issn : 2622-6960, p-issn : 0854-624X

kontak langsung dengan sumber bising, seperti tidak masuk kerja atau pada waktu jam istirahat.

Karyawan yang menggunakan APT ear muff dan ear plug merasakan perbedaan, yaitu ketika menggunakan APT ear muff karyawan merasa kurang nyaman karena ukuran alat yang mempengaruhi gerak kepala saat bekerja, namun ketika menggunakan alat ear muff karyawan masih tetap merasakan pusing, akibat suara bising yang ada dilingkungan tersebut. Sedangkan karyawan yang menggunakan APT ear plug berpendapat bahwa alat tersebut terasa lebih nayaman dibandingkan dengan ear muff, dikarenakan ukuran alat yang kecil dan tidak mempengaruhi gerak kepala karyawan saat bekerja, dan daya redam kebisingan pada alat tersebut lebih baik dibandingkan dengan ear muff.

Hasil penelitian ini sesuai dengan penelitian yang dilakukan oleh Handayani (2010), yaitu ada hubungan antara penggunaan alat pelindung diri dengan kecelakaan kerja pada karyawan diketahui dari nilai $\rho=0,009$ $<0,05$, yang berarti ada hubungan yang signifikan antara penggunaan alat pelindung diri dengan kecelakaan kerja, (Wibisono, 2013).

Penyediaan APT di sebuah
perusahaan belum sepenuhnya
menjamin keselamatan karyawan
seperti yang sudah dijelaskan
sebelumna, bahwa selain penyediaan
APT pengawasan pada saat
penggunaan juga sangatlah
dibutuhkan. Kesehatan dan

keselamatan karyawan dari bahaya penyakit akibat kerja menjadi sebuah kewajiban bagi pengelolah perusahaan karena dengan kurangnya tingkat bahaya yang ada maka tingkat produktivitas perusahaan juga akan ikut meningkat.

Menurut upaya pengendalian (controling) alat pelindung diri (APD) merupakan upaya terakhir yang dapat melindungi kesehatan dan keselamatan karyawan dari potensi bahaya yang mungkin terjadi pada waktu melakukan pekerjaan, setelah pengendalian teknik dan administratif tidak mungkin lagi diterapkan, namun beberapa alat pelindung diri (APD) harus mutlak dikenakan oleh karyawan pada waktu melakukan pekerjaan. Alat pelindung diri ini diantaranya adalah alat pelindung pendengaran (ear muff dan ear plug), sarung tangan, helm dan sepatu. Saat menghadapi potensi bahaya serta sesuai dengan bagian tubuh yang perlu dilindungi. (DEPNAKER, RI 2002. Dalam Efrianis 2007).

\section{KESIMPULAN}

1. Ada pengaruh Intensitas kebisingan dengan kejadian sindroma vertigo pada karyawan di unit produksi

2. Tidak ada pengaruh yang signifikan antara masa kerja dengan kejadian sindroma vertigo.

3. Penggunaan alat pelindung telinga (APT) yang memenuhi syarat pada karyawan lebih rendah mengalami keluhan tekait kejadian sindroma vertigo.

\section{DAFTAR PUSTAKA}

Anonim.

2009.Dampak

kebisingan

terhadap

kesehatan.https://putraprabu.wordpress.com. Diakses pada tanggal 8 september 2015

Anonim. 2010. Definisi Vertigo, gejala, penyebab dan penangannya".http:// digilibunimus.ac.id/files/disk1/121/itptunimus-gdl-sitituslih-6010-2 babii.pdf.Di akses pada tanggal 17 Desember 2014

Efrianis, 2007. Faktor-faktor yang mempengaruhi tenaga kerja dalam pemakaian alat pelindung pendengan di PT Perkebunan Nusantara VI (PERSERO) Kebun Ophir Kabupaten Pasaman Provinsi Sumatra 
Jurnal Sulolipu : Media Komunikasi Sivitas Akademika dan Masyarakat

Vol. 21 No.12021

e-issn : 2622-6960, p-issn : 0854-624X

Barat.http://eprints.ums.ac.id/26126/14/NASKAH PUBLIKASI. pdf. Diakses pada tanggal 20 November 2015.

Handayani dkk. 2010. hubungan antara penggunaan alat pelindung Diri, umur dan masa kerja dengan kecelakaan Kerja pada pekerja bagian rustic di pt borneo Melintang buana eksport yogyakarta. FKM Universitas Ahmad Dahlan, Yogyakarta. http://journal. Vol. 4 No. 3, 09-2010 : 144 - 239. uad.ac.id/index.php/KesMas/article/download/1092/808

Idris, I, D. 2014. Faktor-Faktor Yang Berhubungan Dengan Kelelahan Kerja Pada Petugas Pt.PIn (Persero) Ranting Sidrap Tahun 2014. Skripsi kesehatan lingkungan dan kesehatan kerja STIK Tamalatea Makassar.

Irwandi.2010."vertigo".http://dokterirwandigafma.blogspot.com/2010/07/vertigo.html. Diakses pada tanggal 27 September 2020

Junaidi, Iskandar. 2013. "Pengertian Vertigo" http://dokterirwandigafma.blogspot. com/2010/07/ vertigo.html. Diakses pada tanggal 19 September 2020

Kusumawati, indah, 2012. Hubungan tingkat kebisinga dilingkungan kerja dengan kejadian gangguan pendengaran pada pekerja di PT. X. Skripsi Kesehatan Masyarakat Depok.

Kurniadi, Rizki. 2012. "Asuhan keperawatan pada pasien dengan vertigo".http://asuhankeperawatanonline.blogspot.com/2012/02/ asuhankeperawatan-pada-pasien-dengan 9226.html. Di akses pada tanggal 27 April 2015.

Leksono, ranggan adi. 2009. Gambaran kebisingan. FKM UI.

Lumbantobing, S.M. 2013 :Vertigo Tujuh Keliling. Jakarta: Fakultas Kedokteran Universitas Indonesia.

Peraturan Menteri Tenaga Kerja dan Transmigrasi. Nomor Per.13/MEN/X/2011 Tahun 2011,Tentang Nilai Ambang Batas Faktor Fisika dan Faktor Kimia di Tempat Kerja.

Pendapotan, E T. 2013. Pengaruh Variabel Pendidikan,Upah, Masa Kerja Dan Usia Terhadap Produktivitas Karyawan (Studi Kasus Pada Pt.Gandum Malang). Fakultas Ekonomi dan Bisnis Univ, Brawijaya Malang.

Rahmi Adita. 2003. Analisis hubungan tingkat kebisingan dan keluhan subjektif (non auditory) pada operator SPBU di DKI Jakarta. http://lib.ui.ac.id/file?file=digital/126276-S-5702 Analisis\%20hubungan-HA.pdf. Diakses pada tanggal 16 Juli 2020

Raharjo, Sahird. 2013/04/teori-sampel-dan-sampling-penelitian.html. di akses pada tanggal 27 April 2020

Ridlay, john (Ed). 2016. Health And Safety In Brief, Third Edition. Alih bahasa Soni Astranto, S.Si. Jakarta: Erlangga.

Sriwahyuni, Mus. 2014. "vertigo". http://www.4life-transfer factor makassar.com/2014/08/ vertigo.html. Diakses pada tanggal 13 Mei 2010.

Wahyu, Atjo. 2003. "Pengertian Kebisingan". Sumber http: //www. suarapembaruan.com. diakses pada tangal 11 Juli 2020 
Jurnal Sulolipu : Media Komunikasi Sivitas Akademika dan Masyarakat Vol. 21 No.12021

e-issn : 2622-6960, p-issn : 0854-624X

Wawan. 2012.Vertigo. http://www.scribd.com/doc/132176809/Jurnal-Vertigo-Dr-wawaNLENGKAP. Diakses pada tanggal 11 Juni 2020

Wibawa dkk. 2013. Penentuan tingkat kebisingan lingkungan menggunakan alat Shound Level Meter di sekitar gedung Graha Widya Wisuda. Skripsi Mahasiswa Departemen Teknik Sipil dan Lingkungan Institut Pertanian Bogor.

IWibisono, Bayu 2013. Faktor-faktor yang berhubungan dengan Kejadian kecelakaan kerja pada pekerja Tambang pasir gali di desa pegiringan Kabupaten pemalang tahun 2013. Fakultas Kesehatan Masyarakat Universitas dian nuswantoro Semarang. http://eprints.dinus.ac.id/8009/1/jurnal 13981.pdf

Zulharmans, dkk. 2014.Hubungan Kebisingan Dengan Tekanan Darah Pada Karyawan Bagian Produksi PT Semen Tonasa. Fakultas Kesehatan Masyarakat, Universitas Hasanuddin. http://lib.unnes.ac.id/992/ 1/1927.pdf. Diakses pada tanggan 11-112020. 